\title{
Liquid Level Monitoring and Flow based Liquid Distribution System using PLC and SCADA
}

\author{
Mr. Lavanuru Ashok \\ Research Scholar, \\ Department of Instrumentation, \\ Sri Krishnadevaraya University, \\ Ananthapuramu, A.P., India-515003.
}

\author{
Prof. B. Rama Murthy \\ Research Supervisor (Retd.), \\ Department of Instrumentation, \\ Sri Krishnadevaraya University, \\ Ananthapuramu, A.P., India-515003.
}

\begin{abstract}
The objective of the present work is to design, develop \&testing of the Liquid Level Monitoring and Flow Based Liquid distribution System Using PLC and SCADA In simulation mode. The paper mainly focuses on liquid level monitoring; calculate the flow rate in liquid flow line and the process in automatic mode with proper safety interlock and alarm. The system will provide real time process operation and parameters monitoring by process animations. The essence of this paper is to convert the manually operated plant to fully automated plant for achieving higher accuracy, efficiency and time saving for the process industries.
\end{abstract}

Keywords-Flow, Level, PLC and SCADA

\section{INTRODUCTION}

This present work is implemented in pharmaceutical, petrochemical and some of Oil industries suffered fire incidents with Flammable Liquid Level overflow of tanks and carrying Liquid From one place to another place transforming with manual operation procedure. So the present system proposed to continuous monitor of Liquid Level of tank and safe transferring Liquid from one place to another place. Any manufacturing plant requires continuous monitoring and observation at regular intervals. When it is controlled manually, it increases possibilities of errors at measuring level of a process. To overcome such problems concept of automation came into play. The automation system of oil refinery consists of crude oil storage/pre-treatment system, distillation operations and product storage/dispatch unit in these operations the system consists of feed pumps, valves, motors, flow, level, pressure, temperature monitoring transmitters, unit tanks. The process industries consist of SCADA used to monitor all these parameter values, to start or stop operations from GUI (Graphical user interface) like SCADA and to supervise the unit operations. Control of these operations are from PLC which is consist of the internal storage of instructions for implementing functions such as logic, sequencing, timing, counting and control various types of machine operations, In the PLC/SACAD based boiler automation system have various stages involved in measure and control of water level in storage tank, maintain pressure in stream line, calculating the flow rate in stream line and continuous monitoring and controlling of boiler temperature. The boiler temperature controlled by Variable Frequency Drive (VFD), for preceding all these operations, water maintained at least at $50 \%$. For sensing water level PID controller is used in PLC. If water is not available minimum
$50 \%$ then adjust feed valves to their positions to feed water and then control temperature.

Waste water treatment is the process of remove contaminants wastage minerals from wastewater and converts it into an effluent pure drinking water that can be returned to the water cycle with minimum impact on the environment, or directly reused. Wastewater treatment process consists of the following operations like filtering, elimination of the colloids through the process physical-chemical clotting and flocculation, treatment to regulate the $\mathrm{Ph}$ of the water, biological treatment process, finally decanting and sludge extraction. The complete sequential process executed with automation like PLC/SCADA system, in the system continuously Monitoring and controlling of process parameters like flow rates, level, temperature and various control valves.

In food, chemical and petrochemical industry, level measurement and monitoring of liquid substances products in tanks and different types of storage places, in this process we must know the level of the storage tanks. So most of the process industries used PLC/SCADA system to measure and display of their volume of storage tanks, the process industries have some of liquids too expensive and flammable so the during the loading and unloading operations, leakage control, continuous monitoring of liquid storage tanks

\section{SYSTEM IMPLEMENATATION}

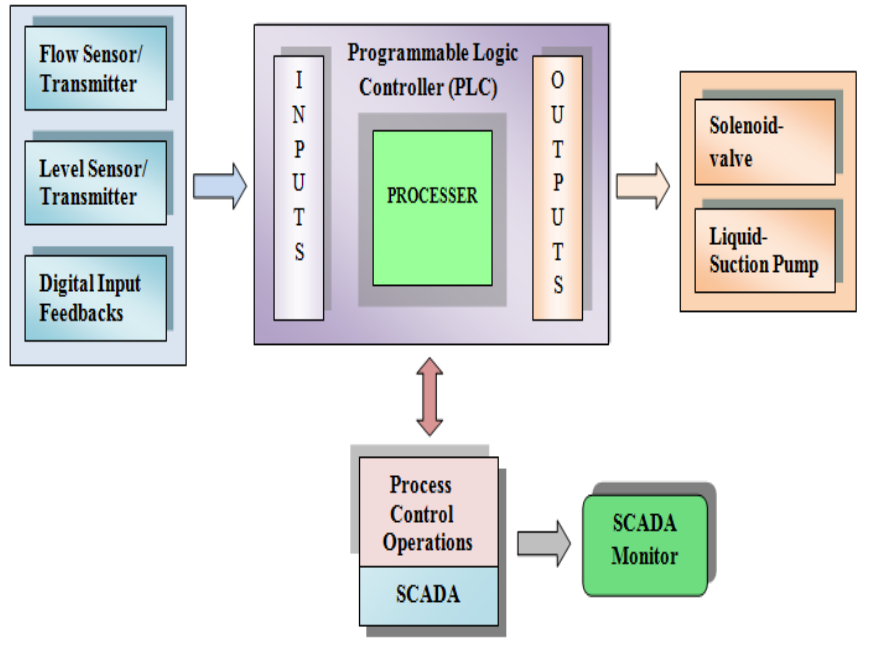

Fig. 1. Block diagram of Proposed System 


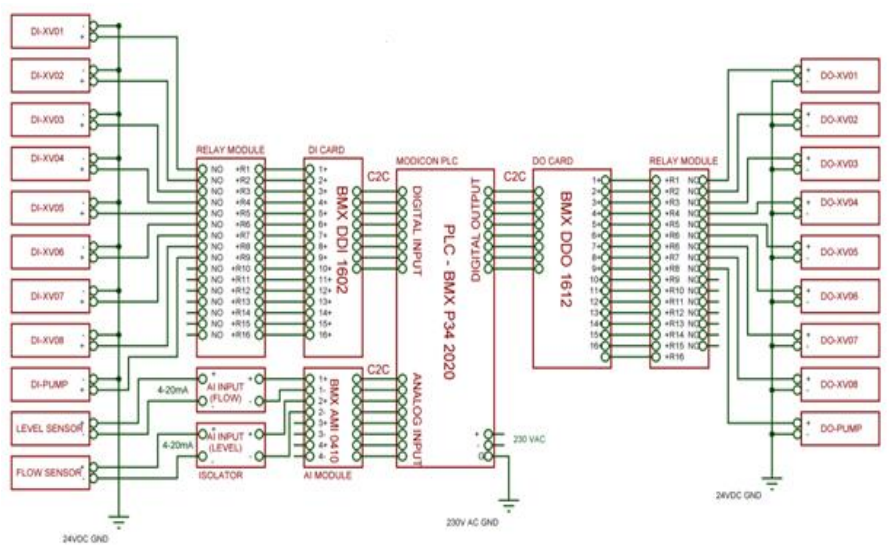

Fig. 2. Schematic Diagram

The block diagram consists of the following units
1. PLC
2. SCADA PC
3. Flow sensor
4. Level sensor
5. Digital Inputs
6. Pump CMDs
7. Valves CMDs
8. Monitor
9. Printer

\section{A. Programable Logic Controller}

Programmable Logic Controller (PLC) is a digital computer used for the automation of various electromechanical processes in industries. PLC consists of a microprocessor which is programmed using the computer language. The program is written on a computer and is loaded into the PLC via communication cable. These loaded programs are stored in nonvolatile memory of the PLC. During the transition of relay control panels to PLC, the hard wired relay logic was exchanged for the program fed by the user. A PLC is an example of a hard real time system since output result must be produce in response to input condition within a limited time, otherwise unintended operation will result. A visual programming language known as the Ladder Logic Programming (LLP) and Functional Block Diagram (FBD) Language has been used to program the PLC.

\section{B. Supervisory Controland Data Acquistion System}

SCADA stands for Supervisory Control and Data Acquisition. As the name indicates, it is not a full control system, but rather focuses on the supervisory level, it is used to monitor and control plant or equipment. The control may be automatic or initiated by operator commands. The data acquisition is accomplished firstly by the PLC scanning through field inputs connected to the PLC. SCADA provides several unique features that make it a particularly good choice for many control problems. The features are as follows

- The computer control primary equipment, record an store a very large amount of data from process.

- The operator can incorporate real data simulations into the system.
- The operator is assist by computer that recommends actions to keep the system safety.

- Many types of data can be collected from the PLC; this creates online the image of the System.

\section{Flow Sensor/Transmitter}

A Flow sensor/transmitter is a device that they know exactly how much fluid is passing through a point at any Liquid flow line. The flow meter is used to measure linear, non-linear, mass or volumetric flow rate of a liquid or gas. Many industrial flow meters have to work with fluids which may be corrosive in nature or may contain foreign matters, but the equipment may be relatively large and of fixed type. The choice of a particular flow metering device are the various performance parameters like range, accuracy, repeatability, linearity, dynamic response, type of output like analog/digital. The process industries preferred to measure the flow rate of liquid flow line used to vertex-shedding flow meters.

The vertex-shedding type flow meters operate on the principle that if a bluff body (non-streamlined body) or an obstruction is placed in a fluid stream, vortices are shed alternately on each side of the bluff body. The vertex shedding frequency of the bluff body is a measure of the average flow velocity of the fluid flow. The output of the flow meter in both cases is electrical and can be suitably processed to either indicate instantaneous flow or totalized flow.

\section{Level Sensor/Transmitter}

A Level sensor/transmitter is a device used to measure and monitoring of the level of liquid within a tank, the level measurement can be either continuous or point values. Continuous level sensors measures the level within a specified range and determines the exact amount of substance In a certain place, So present process plants proposed to continuous monitor of Flammable Liquid Level of tank used with Differential Pressure Level Transmitter (DPLT) or hydrostatic pressure level measurement device(HPLMD).

The hydrostatic pressure created by a liquid is directly to the height of the liquid column, a pressure gauge is installed at the bottom or on the side of the tank containing the liquid. The rise and fall of the liquid level causes a corresponding increase or decrease in the pressure, which is proportional to the liquid level. The scale of the pressure gauge is calibrated in the units of level measurement.

\section{E. Digital Signalling}

Digital Input means it is a discreet electrical signal with specified voltage above/below a specific threshold voltage, normally in process industries designed for different voltage levels like $0-5 \mathrm{Vdc}, 0-12 \mathrm{Vdc}$ or $0-24 \mathrm{Vdc}$ as depends upon the process requirements. This Digital Inputs indicates status and position of the process instruments like solenoid Valves status open or close position.

A solenoid valve is an electromechanical actuated valve they have a simple form of an electromagnet consisting of a coil of insulated copper wire. A solenoid valve is an electromechanical valve frequently used to control the flow of liquid or gas. A 2-way solenoid valve have 2 ports; if the 
valve is open, then the two ports are connected and fluid may flow between the ports; if the valve is closed, then ports are isolated. If the valve is open when the solenoid is not energized, then the valve is termed normally open (N.O.). Similarly, if the valve is closed when the solenoid is not energized, then the valve is termed normally closed

\section{SOFTWARE IMPLEMENATATION}

Ladder Logic Programming (LLP) and Functional Block Diagram (FBD) Language has been used to program the PLC. For this purpose Unity pro XL Simulation Software (PLC) and vijeo citect SCADA has been used as simulator. The programming logic has been set according to the process flow and Tantalizer (TOT) has been used in the program to tantalize the cumulative liquid Quantity while liquid flows through the Flow meter.

\section{ALGORITHM}

The Algorithm of entire system is presented below as shown in the Fig 3.

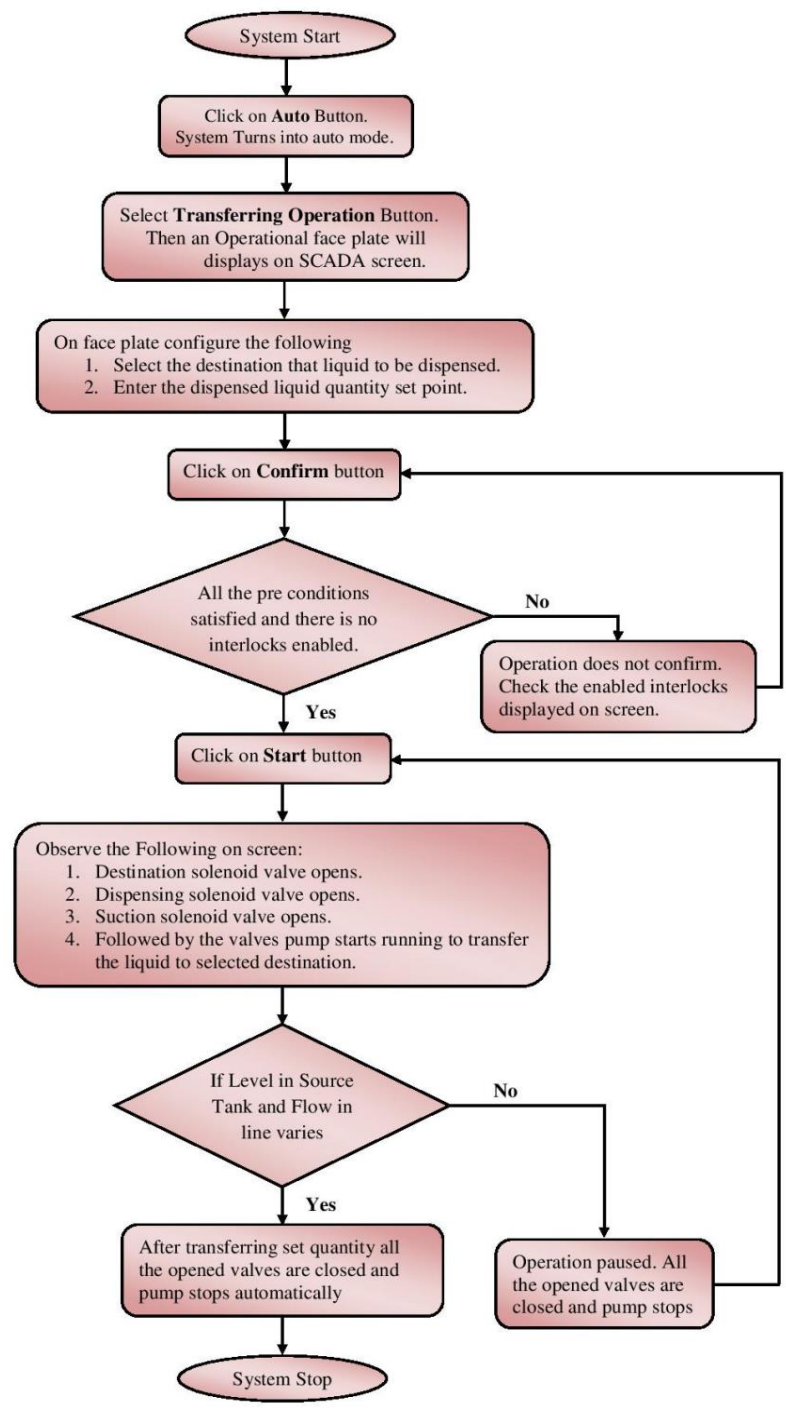

- Click on Auto button from SCADA screen to keep the system in Auto mode.

- Then select the Transferring button for transferring liquid/Solvent

- There is a face plate related to transferring operations appears on SCADA screen

- Select the destination where liquid/solvent is to $b$ transferred.

- Enter the set quantity that much of liquid transferred into selected destination.

- Click on confirm button.

- If all the interlocks satisfied then operations will confirmed otherwise doesn't confirmed.

- If operation confirmed then click on Start button.

- Observe destination, dispensing, suction solenoid valves are opened followed by pump starts running to transfer the liquid/solvent from source tank to destination.

- If Level in source tank decreases and flow sensor in line senses the liquid/solvent flow then operation remains continues otherwise operation will be paused automatically. That means all the opened valves are closed and pump stops.

- After transferring the liquid/solvent by the set quantity given then operation completed automatically and opened valves are closed and pump stops.(Or)While liquid/solvent pumping, when flow sensor totalizes the flow rate equivalent to the given set quantity then operation completed automatically and opened valves are closed and pump stops.

A solenoid valve is an electromechanical on/off valve operates with $12 \mathrm{v}$ dc power supply. The solenoid valves operating from SCADA system then arrange the feedbacks for valve position status and commands for valve opening and closing in remote mode. The program written into process consideration, suppose the two feedbacks i.e., open feedback signal, closed feedback signal and open command signal of a solenoid on/off valve from field will be connected with PLC configured in software. The basic concept of operation of solenoid valve communicates with PLC under Supervisory of SCADA system. Following are the list of required PLC digital input and digital output channels.

- \%I0.4.2 (ST09_XV01_OFB) is the Digital input signal from open feedback of valve.

- \%I0.4.2 (ST09_XV01_OFB) is the Digital input signal from closed feedback of valve.

- \%Q0.9.1 (ST09_XV01_CMD) is the Digital output signal to open command of valves.

Following figure represents that PLC Hardware Configuration and channels.

Fig. 3. Software Algorithm 


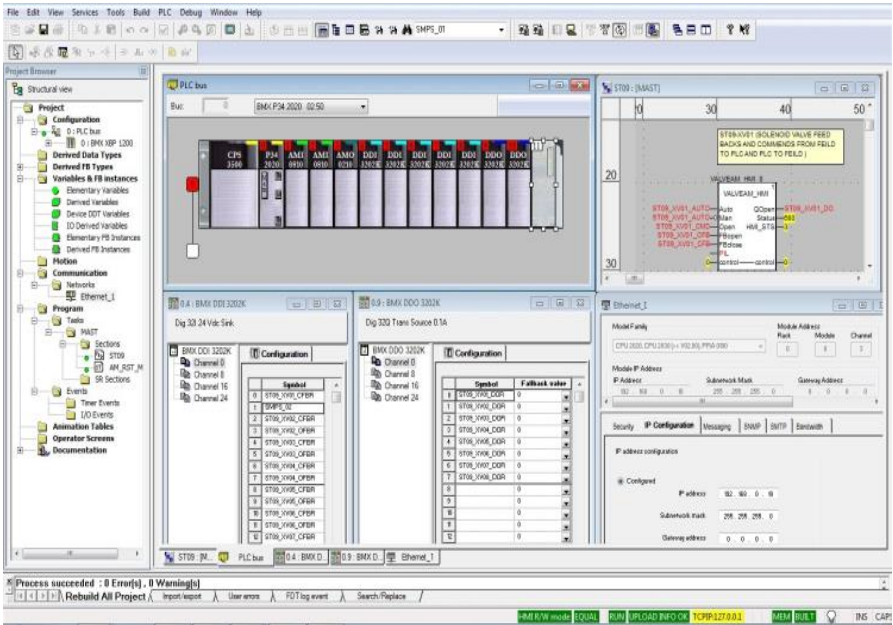

Fig. 4. PLC Hardware Configuration

The above address are configured for the ST09_XV01 solenoid valve, the valve in normally closed condition ST09_XV01_CFBtag address is \% I0.4.2 High(ONE) in PLC System. If the valve in normally open condition ST09_XV01_OFB tag address is \% I0.4.3 High (ONE). When in operator need to open the valve simply high the ST09_XV01_CMD tag address \% Q0.9.1 need to High (ONE) from PLC, then solenoid valve normally open and \% I0.4.2 address LOW(ZERO) and \% I0.4.3 high(ONE) until \% Q0.9.1 is high. Finally the PLC memory address linked with the SCADS memory address, when changes in the PLC address location then automatically changed in SCADA address locations as depend upon the software configuration following figure.

\section{A. Solenoid Valve Indication in SCADA screen}

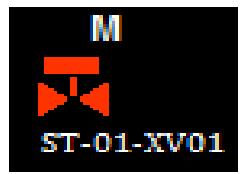

Fig. 5. Solenoid valve Indication

Mode - This field will represent valve Operating Mode.

Tag - This field will represent tag of Valve.

Following are the different types of valve position status and significant colors represented.

\begin{tabular}{|c|l|c|}
\hline S. No. & \multicolumn{1}{|c|}{ Description } & $\begin{array}{c}\text { SCADA } \\
\text { Indication }\end{array}$ \\
\hline 1 & Valve Closed & \\
\hline 2 & Valve Open & \\
\hline 3 & $\begin{array}{l}\text { Valve Feedback } \\
\text { Error/Valve Fail }\end{array}$ & \\
\hline
\end{tabular}

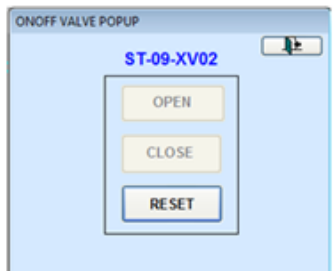

Fig. 6. Solenoid valve Status/Control.

By click on off valve symbol on SCADA graphics by user, using "display popup" as event of button the below popup will be displayed as a child screen of main screen. There is a facility to close the popup after controlling on off valve in that popup. The three buttons in the below popup is executes their respected functions. These buttons are enable or disable affected by the mode of operations and interlocks explained in following table.

\section{B. Pump/Motor Block in SCADA screen}

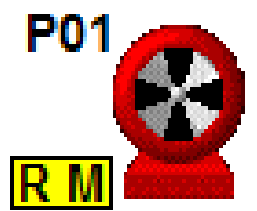

Fig. 7. Pump/Motor Indication

Tag - This field will represent tag of Pump.

Mode - This field will represent pump Operating Mode.

The motor states are follows as below figure.

TABLE I. PUMP/MOTOR STATUS

\begin{tabular}{|c|l|c|}
\hline S.No. & Description & $\begin{array}{c}\text { SCADA } \\
\text { Indication }\end{array}$ \\
\hline 1 & Pump idle & \\
\hline 2 & Pump Running & \\
\hline 3 & Pump Trip/Fail & \\
\hline
\end{tabular}

\section{Flow Monitoring Block in SCADA screen}

A Flow Meter is a device used to measure the instant flow rate or quantity of a solvent, liquid or gas passing through a pipeline. Flow Transmitter is the upgrade of flow meter where transmit the flow value data to monitoring system (SCADA). Flow data from Flow Transmitter in the form of 4 $20 \mathrm{~mA}$ (mille amps) currents.

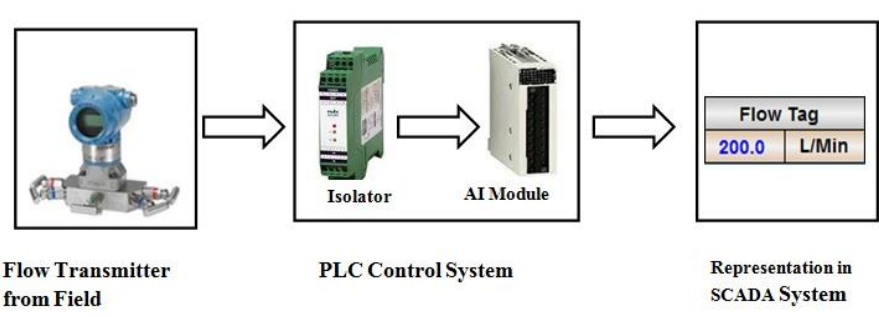

Fig. 8. Flow Monitoring

Flow transmitter is the device used to transmit data from a flow sensor over the two-wire 4-20 mA current loop. The transmitter converts the physical signal such as flow rate into the necessary electrical signal in the form of 4 to $20 \mathrm{~mA}$ current loop. The scaling of loop current is adjusted by the transmitter to be proportional to the actual input physical signal. The transmitter typically uses $4 \mathrm{~mA}$ output to represent the calibrated zero input or $0 \%$, and $20 \mathrm{~mA}$ output to represent a calibrated full-scale input signal or $100 \%$. The relationship between the output current value and transmitter converts the physical process value is set by calibration of the transmitter, which assigns a different range of engineering units to the span between 4 and $20 \mathrm{~mA}$. The transmitter signals are connected to $4-20 \mathrm{~mA}$ loop powered isolator is typically used to provide an isolated 4- 20mA current loop from any existing 
4-20mA loop. This isolated 4-20mA can then be connected to any input stage without affecting other signals connected to the system. Alternatively the isolator can be used to isolate signals from non-isolated transmitters or as a noise reduction device.

Typical analog flow signal from isolator is connected to AI Module. Analog input signals are current or voltage. Analog input modules convert analogy signals to digital words as following table. The I/Os are connected through a program called as Software configuration, as there is no direct-physical relation between input and outputs. The program is written into process consideration. Flow signal from field will be connected with PLC based on communication protocol, configured in software as follows.

- \%IW0.1.1 is the Analog input signal from flow sensor/transmitter.

TABLE II. ANALOG DATA PROCESSING

\begin{tabular}{|c|c|c|c|}
\hline S.No. & $\begin{array}{c}\text { Analog Data } \\
\text { in AI Module }\end{array}$ & $\begin{array}{c}\text { Signed data by } \\
\text { the Processor }\end{array}$ & $\begin{array}{c}\text { Scaling range } \\
\text { in SCADA }\end{array}$ \\
\hline 1 & $4 \mathrm{~mA}$ & 0 & $0 \mathrm{LPM}$ \\
\hline 2 & $8 \mathrm{~mA}$ & 2500 & $50 \mathrm{LPM}$ \\
\hline 3 & $12 \mathrm{~mA}$ & 5000 & $100 \mathrm{LPM}$ \\
\hline 4 & $16 \mathrm{~mA}$ & 7500 & $150 \mathrm{LPM}$ \\
\hline 5 & $20 \mathrm{~mA}$ & 10000 & $200 \mathrm{LPM}$ \\
\hline
\end{tabular}

\section{MONITORING SCREEN}

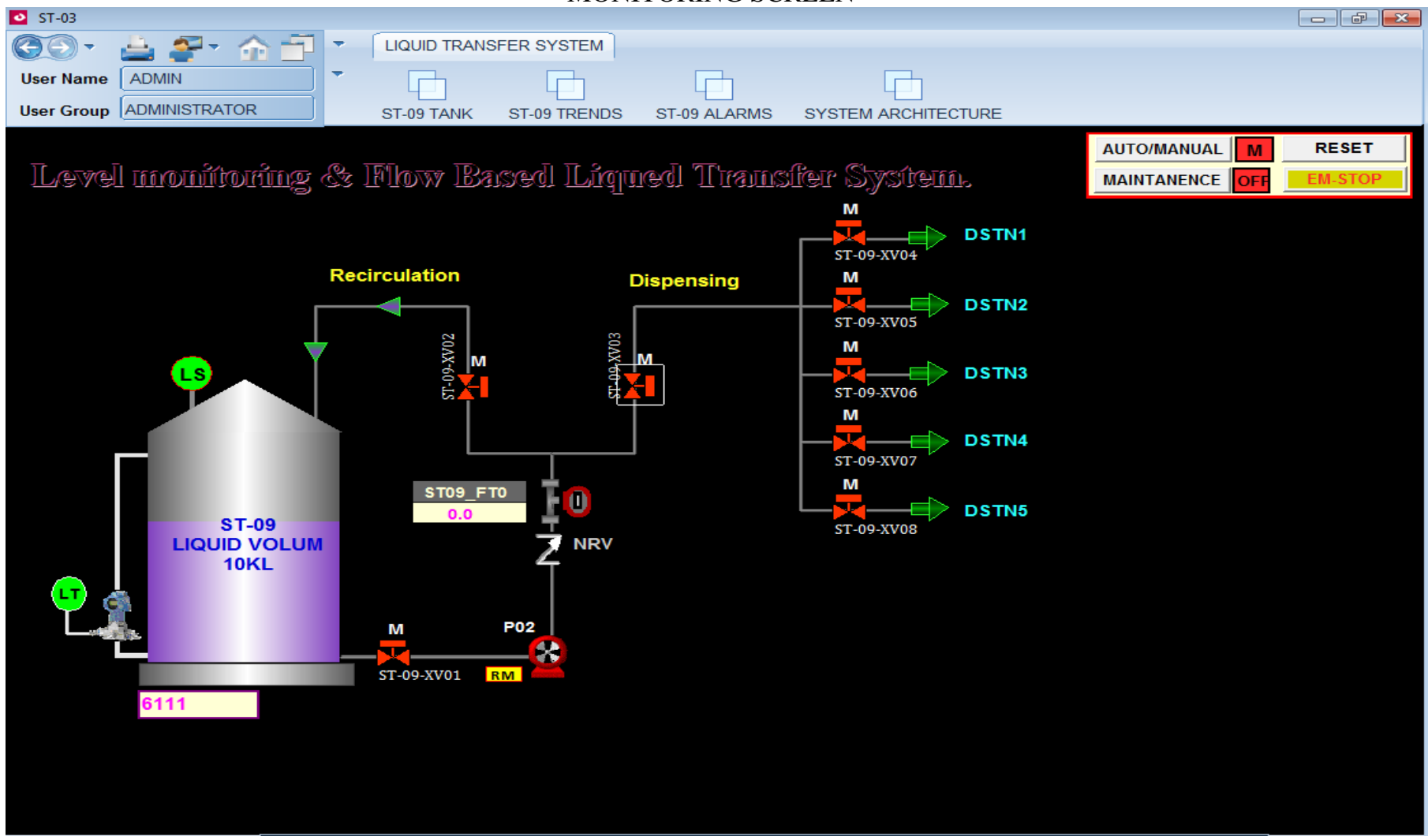

Fig. 10. Manual Mode Screen 
First keep the process in auto mode by click on Auto button from SCADA screen.
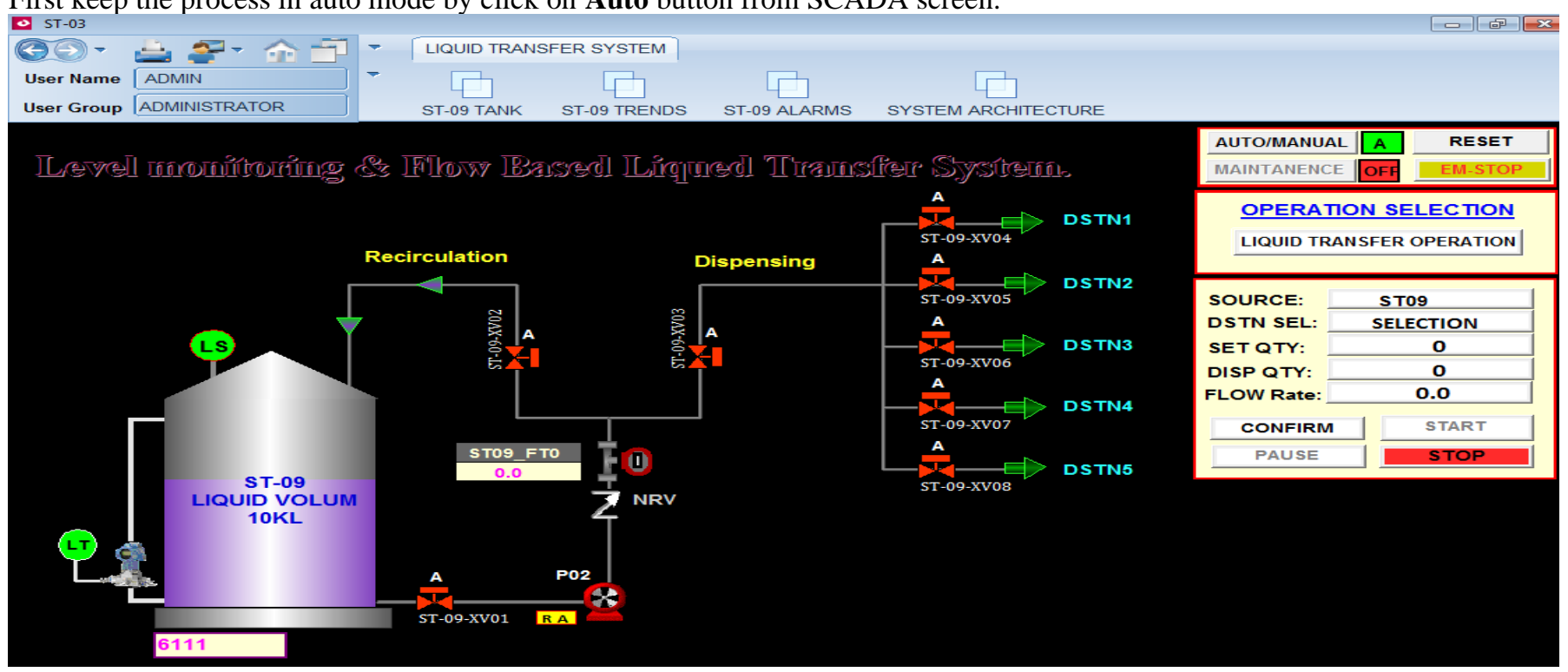

Fig. 11. Auto Mode Screen

Select the operation needed to be performed i.e. transferring. Then select the destination which could be a defined destination. Enter the quantity as a set point which needed to transfer from source storage tank to destination.
Click on Confirm button for transferring from source tank to destination, before confirming the process following are the Safety interlocks or pre check conditions for dispensing.

- On/Off valves, pumps, \& level switches status indication should be provided with red color animations in operating SCADA screen.

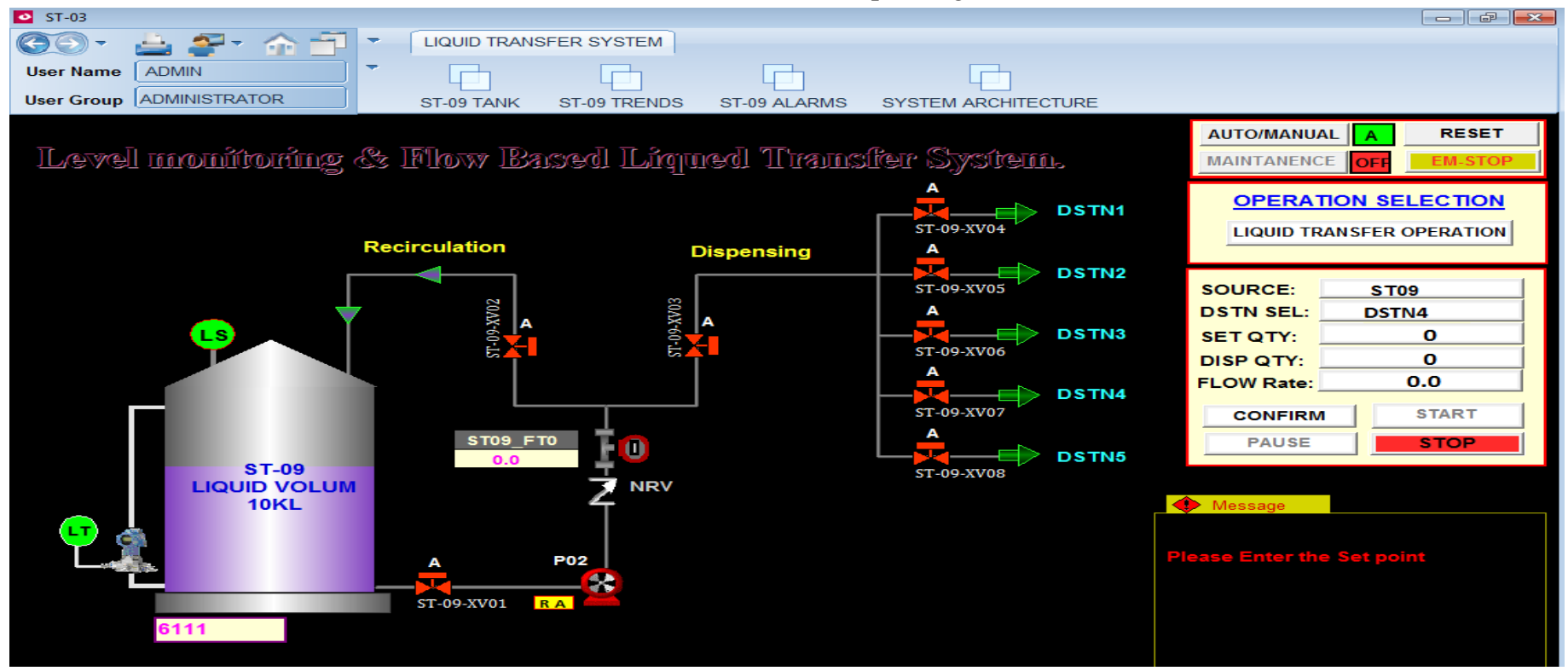

Fig. 12. Interlock warning Screen

- Level in the storage tank should be maintained. Entered set quantity of the solvent should available in the selected source Tank.

- Continuous level monitor from level transmitters of storage tanks is required.

- Continuous flow monitor on pipe line is required.
The system will have all the above pre check conditions and any one of interlock is not satisfied then operation does not confirmed. The enabled interlock displayed on SCADA operating screen, operator has to check and confirm the operation. Interlock enabled then screen appears as follows. 
If operation confirmed then screen appears as follows.

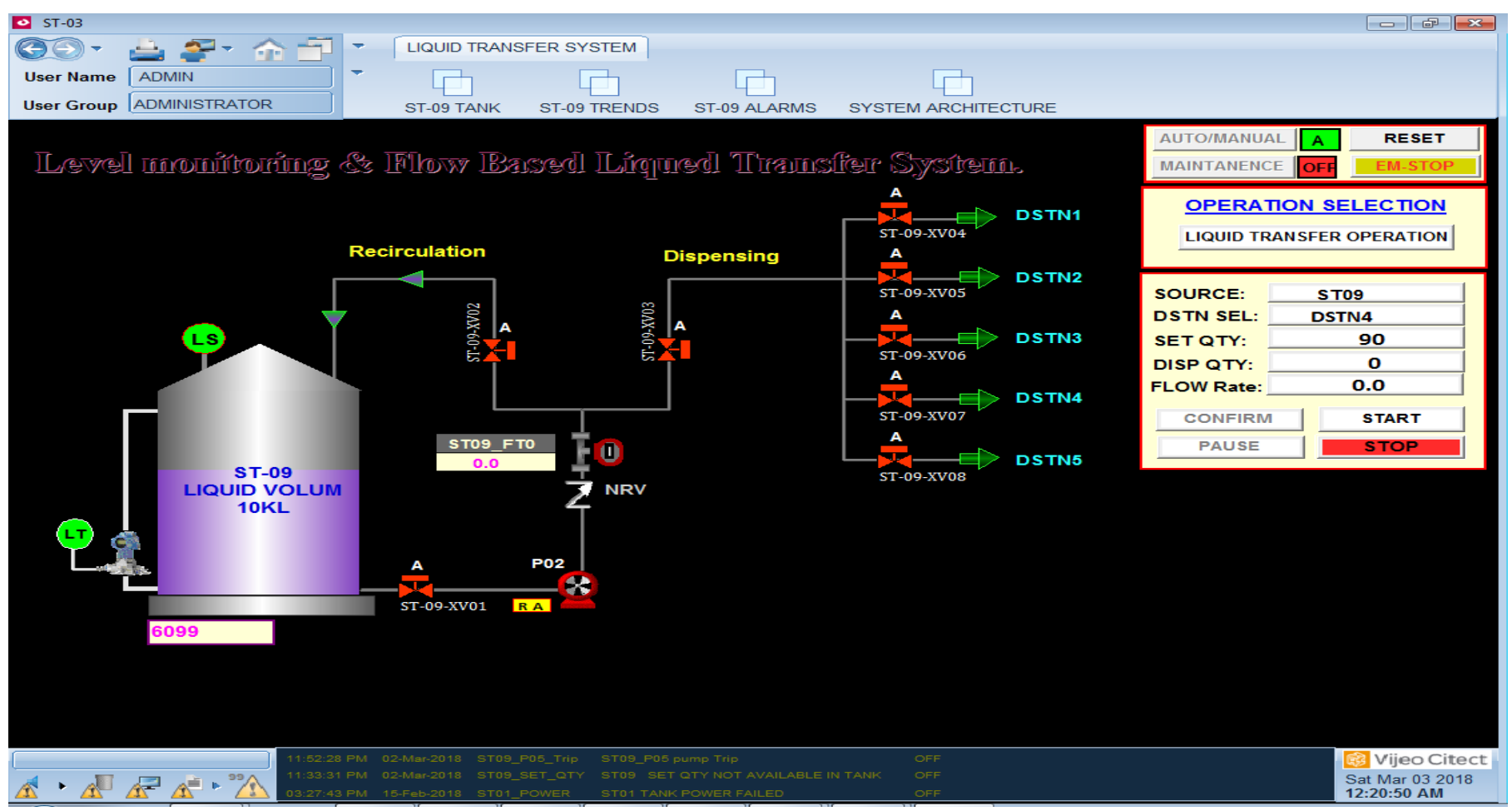

Fig. 13. If operation confirmed then screen appears as follows

After confirm click on Start button to transfer operation. Destination, transferring, suction solenoid valves are opened followed by pump starts running to transfer the liquid from source tank to destination. SCADA system will have Flow animation of solvent, on off valves and pump status with color indication during dispensing.

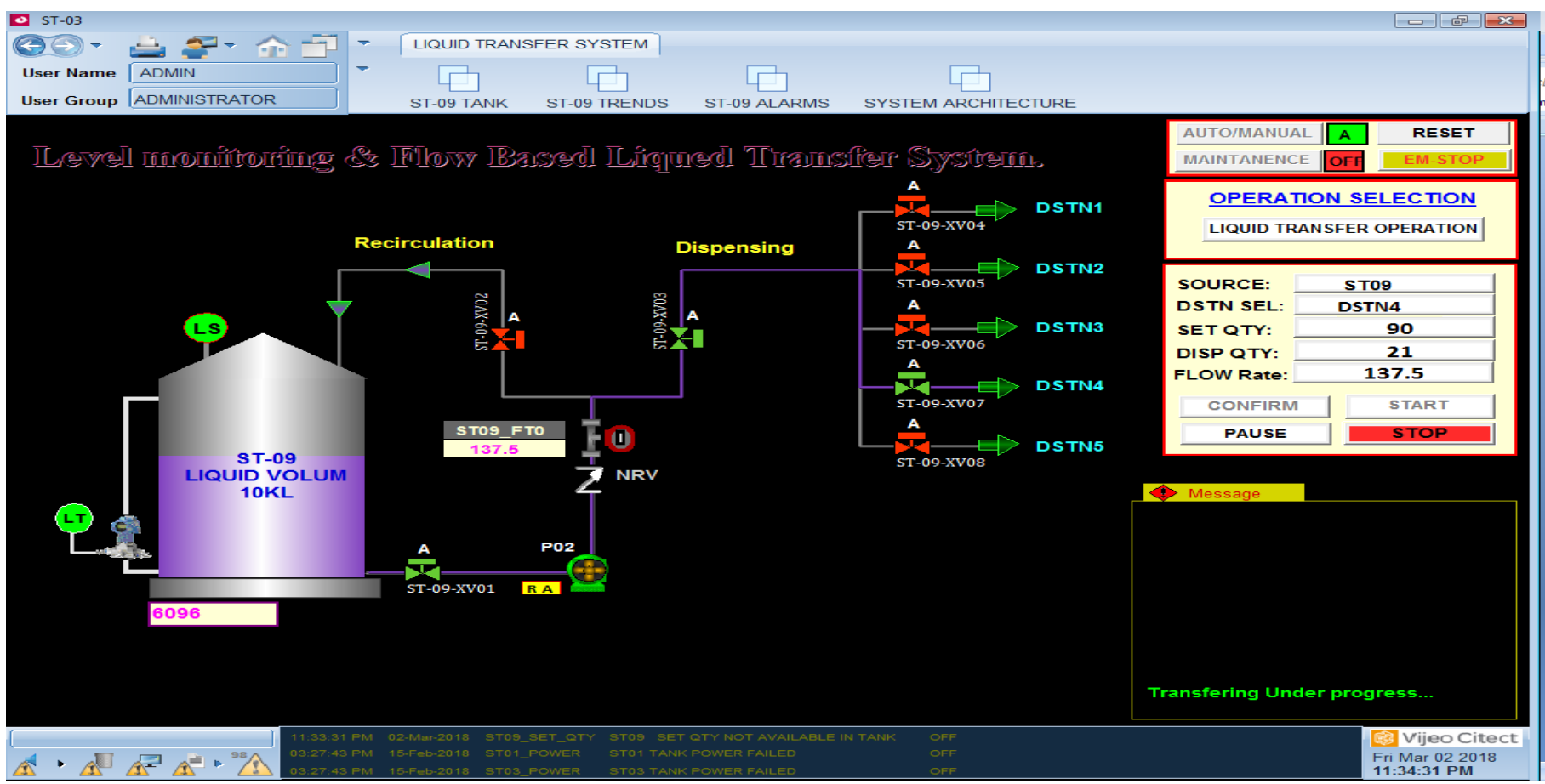

Fig. 14. Liquid dispensing operation screen

If any one of the following deviation occurs in the middle of the process then the process will be paused.
- If there is no change in the storage tank level and if there is no change in the line flow. 
- If pump dry run or tripped or failed.

- If any one of the dispensing valves open feedback is not received to PLC or valve fails.
- During dispensing of the solvent if any one of other valve is opened manually from field (override).

- If liquid level/Level switch in the storage tank goes low.

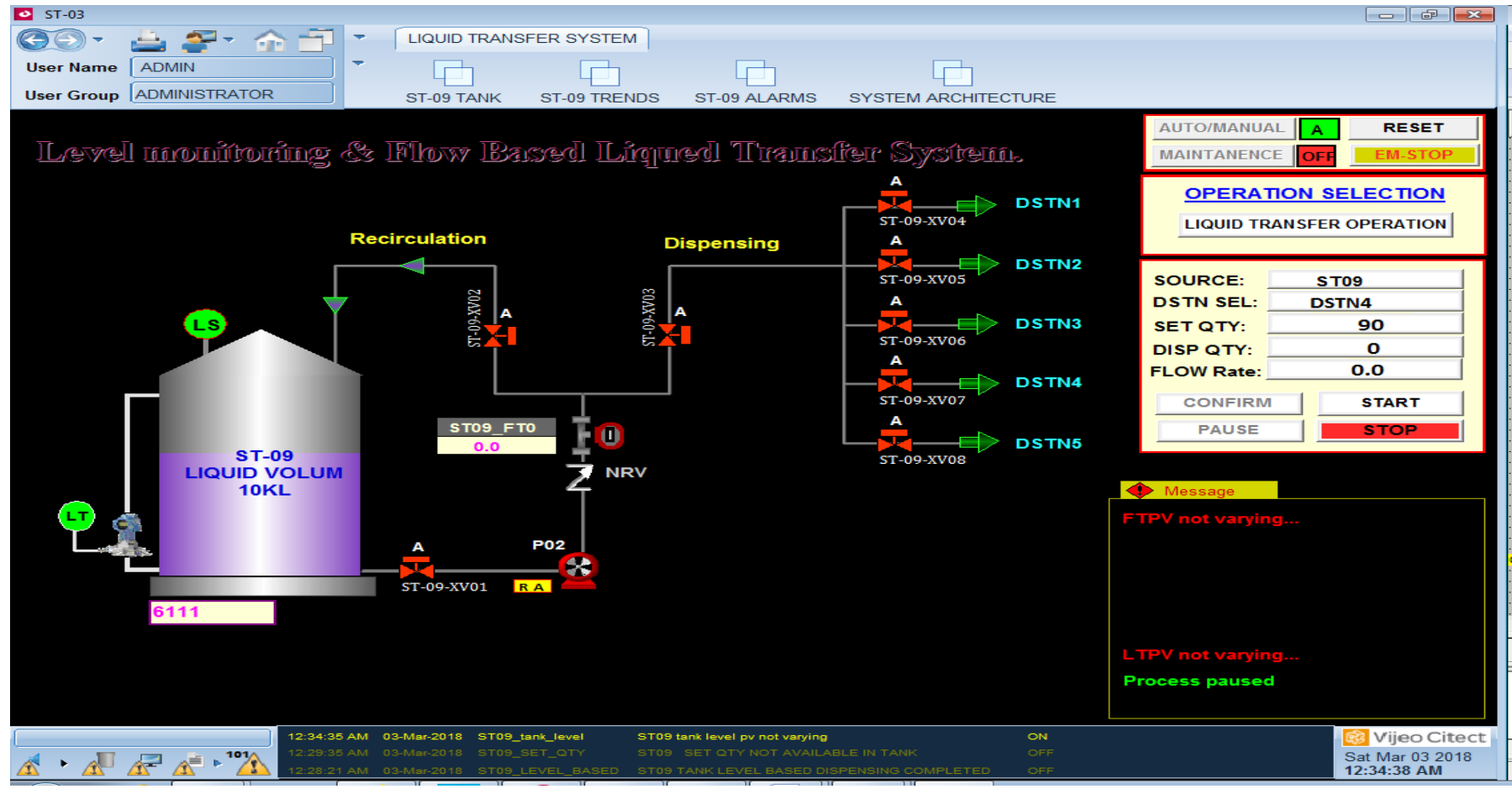

Fig. 15. Interlock enabled then pause screen.

The enabled interlock displayed on SCADA operating screen. It must be corrected or instrument need to be trouble shoot. Then user comes back and process start again by click on start button.

While liquid pumping, when flow sensor totalizes the flow rate equivalent to the given set quantity then operation
Completed automatically pump turns off and corresponding valves are closed. Then the process complete successfully. Stop is provided in SCADA screens, which stops transferring operations if necessarily.

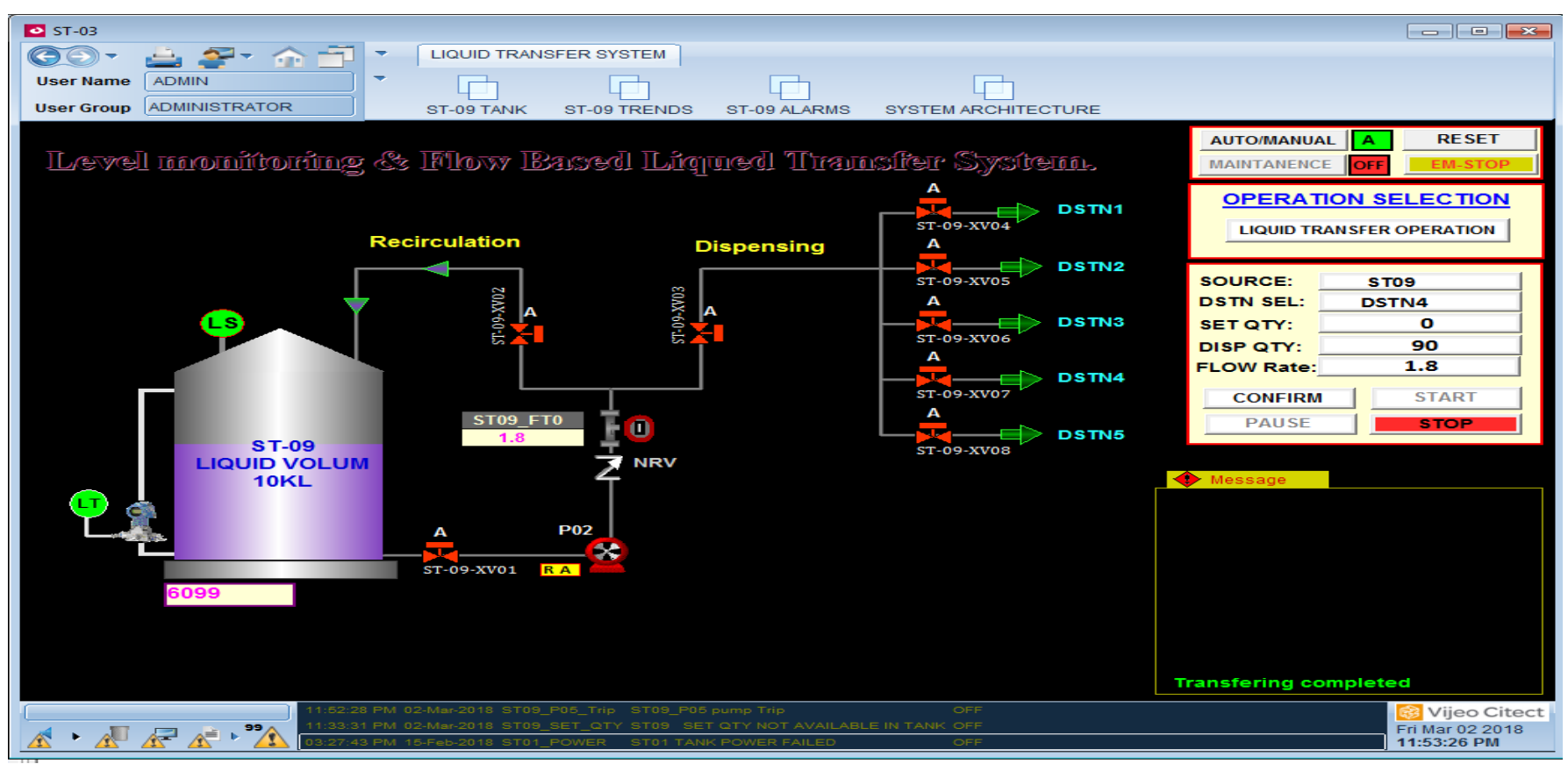

Fig. 16. Liquid dispensing completed screen result 


\section{RESULTS AND DISCUSSION}

The experimental work has been carried out as detailed in Section 4 , to perform online monitoring and control of level and flow in a flow based liquid transportation system.

\section{CONCLUSION AND FUTURE SCOPE}

A SCADA model is developed for the liquid level monitoring and transfer system used for effective online monitoring and control of liquid flow rate by regularizing the different set points. From the experimental results, PLC based adaptive controller enhances the performance remotely through SCADA system. The experimental analysis shows that PLC based SCADA system perform accurate process operations and the speed of the operation too faster than manual system. Automation based controlling system provides fair transient response with minimum error indices of $0.92 \%$ and good quality comparison with manual system. Hence the overall performance of the automation system enhanced quality of operation by the PLC based automation controller as compared to manual system. Also, PLC automation system provides control action at appropriate time which prevents the occurrence of major risk factors like Flammable blasts in the long distance oil transmission system.

\section{REFERENCES}

[1] Gowri Shankar, K. (2008). Control of Boiler Operation using PLC SCADA. Lecture Notes in Engineering and Computer Science. 2169

[2] Moursi, Israa \& Mohy El-Din, Loay. (2014). SCADA system for oil refinery control. Measurement. 47. 5-13. 10.1016/j.measurement.2013.08.032

[3] Tawackolian, Karsten \& Büker, Oliver \& Hogendoorn, Jankees \& Lederer, Thomas. (2013). Calibration of an ultrasonic flow meter for hot water. Flow Measurement and Instrumentation. 30. 166-173. 10.1016/j.flowmeasinst.2012.05.003.

[4] Humoreanu, Bogdan \& Nascu, Ioan. (2012). Wastewater treatment plant SCADA application. 2012 IEEE International Conference on Automation, Quality and Testing, Robotics, AQTR 2012 Proceedings. 10.1109/AQTR.2012.6237776.

[5] SHAKYAWAR2P. G., "AUTOMATION OF OIL AND GAS REFINERY PROCESS USING PLC \& SCADA”, IJESAR, vol. 2, no. 3, Jun. 2016

[6] P. Ward, Michael. (2019). An architectural framework for describing Supervisory Control and Data Acquisition (SCADA) systems /.

[7] V. Rajeswari, L. Padma Suresh and Y. Rajeshwari, "Water storage and distribution system for pharmaceuticals using PLC and SCADA," 2013 International Conference on Circuits, Power and Computing Technologies (ICCPCT), Nagercoil, 2013, pp. 79-86

[8] Y. Kondratenko, O. Korobko, O. Kozlov, O. Gerasin and A. Topalov, "PLC based system for remote liquids level control with radar sensor," 2015 IEEE 8th International Conference on Intelligent Data Acquisition and Advanced Computing Systems: Technology and Applications (IDAACS), Warsaw, 2015, pp. 47-52

[9] I. Morsi, M. E. Deeb and A. E. Zwawi, "SCADA/HMI Development for a Multi Stage Desalination Plant," 2009 Computation World: Future Computing, Service Computation, Cognitive, Adaptive, Content, Patterns, Athens, 2009, pp. 67-71.

[10] Bela, Genge \& Siaterlis, Christos. (2013). Physical process resilience-aware network design for SCADA systems. Computers \& Electrical Engineering. 40. 10.1016/j.compeleceng.2013.11.018.

[11] Sangeetha, Lakshmi \& Naveenkumar, B \& Ganesh, A \& Bharathi, N. (2012). Experimental validation of PID based cascade control system through SCADA-PLC-OPC and internet architectures. Measurement. 45. 643-649. 10.1016/j.measurement.2012.01.005.
[12] Li, Jiangye \& Xiong, L \& Peng, N \& Dong, Bob \& Wang, P \& Q. Liu, L. (2013). Measurement and Control System for Cryogenic Helium Gas Bearing Turbo-expander Experimental Platform Based on Siemens PLC S7-300. 1573. 10.1063/1.4860918.

[13] Biswal, Jayashree \& Pant, Harish \& Goswami, Sunil \& Samantray, J \& Sharma, V.K. \& Sarma, K.S.S.. (2017). Measurement of flow rates of water in large diameter pipelines using radiotracer dilution method. Flow Measurement and Instrumentation. 59. 10.1016/j.flowmeasinst.2017.12.014.

[14] C. Baker, Roger \& Gimson, Chris. (2001). The effects of manufacturing methods on the precision of insertion and in-line thermal mass flowmeters. Flow Measurement and Instrumentation. 12. 113-121. 10.1016/S0955-5986(01)00005-X.

[15] Venugopal, A \& Agrawal, Amit \& Prabhu, S. (2011). Review on vortex flowmeter-Designer perspective. Sensors and Actuators Aphysical - SENSOR ACTUATOR A-PHYS. 170. 8-23. 10.1016/j.sna.2011.05.034.

[16] M. G. Figueiredo, Joao \& da Costa, J.M.G.. (2007). A Concept for an Operational Management System for Industrial Purposes. 1 - 6. 10.1109/WISP.2007.4447549.

[17] Automatic Control of Temperature and Level of CSTR Using PLC and SCADA

[18] BR Bhagwat, VG Asutkar - International Journal of Science \& Technology ISSN ..., 2011

[19] Das, Rishabh. (2013). Automation of Tank Level Using Plc and Establishment of Hmi by Scada. IOSR Journal of Electrical and Electronics Engineering. 7. 61-67. 10.9790/1676-0726167.

[20] Hui Yang, Xin. (2014). Design and Research for a Boiler Steam Drum Control System Based on PLC. Advanced Materials Research. 1030-1032. 1442-1444. 10.4028/www.scientific.net/AMR.1030 1032.1442

[21] Younas, Umair \& Durrani, Sajjad \& Mehmood, Yasir. (2015) Designing Human Machine Interface for Vehicle's EFI Engine Using Siemen's PLC and SCADA System. 205-210. 10.1109/FIT.2015.44.

[22] Wiliem, Leonard \& J. Hargreaves, Douglas \& F. Stapelberg, Rudolph \& Yarlagadda, Prasad. (2007). Development of Real-Time Data Filtering for SCADA System. Journal of Achievements in Materials and Manufacturing Engineering. 